\title{
Comparing Effect of 'Summarizing', 'Question-Answer Relationship', and 'Syntactic Structure Identification' on the Reading Comprehension of Iranian EFL students
}

\author{
Fatemeh Hemmati (Corresponding author) \\ Payam-e-Nour University, Tehran, Iran \\ E-mail: Fatemehhemmati2002@yahoo.co.uk \\ Safoora Bemani \\ Payam-e-Nour University, Tehran, Iran \\ E-mail: sbemanie@yahoo.com
}

Received: 02-09- 2012

Accepted: 01-10- 2012

Published: 01-01- 2013

doi:10.7575/ijalel.v.2n.1p.151

URL: http://dx.doi.org/10.7575/ijalel.v.2n.1p.151

\begin{abstract}
This study aimed at comparing the effects of 'question-answer relationship strategy', 'summarizing', and 'syntactic structure identification training'on the reading comprehension of Iranian EFL learners. The participants were sixty (34 women and 26 men) intermediate students who answered an English reading comprehension test consisting of three reading passages as the pretest. During the treatment, the students in the first group were supposed to summarize the passages. The subjects in the second group familiarized with the syntactic structure identification strategy and the ones in the third group were taught the question-answer relationship strategy. At the end of the treatment, an English reading comprehension test similar to the pretest was administered to the groups as a posttest. The results suggested that there is statistically significant difference between the reading comprehension abilities of the three classes. Furthermore the use of QAR strategy led to better comprehension of reading texts with syntactic structure training and summarizing between which there was no significant difference.
\end{abstract}

Keywords: Reading comprehension, summarization, question-answer relationship, syntactic structure

\section{Introduction}

It is generally agreed that well-developed reading comprehension ability is the key to students' academic success. This comprehension ability is not a passive state which one possesses, but it is an active mental process which needs to be nurtured and improved. According to Resnick (1984), it is a process in which one "uses external information" to construct new knowledge. If the process is to occur, comprehension a complicated combination of skills in which students their understanding of various elements, the how of finding main ideas and details and make a distinction between the two. By taking the intricacy of this comprehension into account, educators must cope with the problem of specifying the best strategy for the purpose of contributing to its development. With this in mind, this research investigated the most frequently used learning strategies including summarizing, question-answer relationship, and syntactic structure training.

As many language teaching specialists such as Grabe (1991) have pointed out, both reading theory and practice have undergone numerous changes in the second half of the previous century. Current researches have presented fresh ways for teaching reading comprehension(RC) skills to learners of a second or foreign language. From the late 1970s, according to Grabe (1991) "Reading was characterized as an active process of comprehending and students needed to be taught strategies to read more efficiently." (p.337)

Dugan (1997) explains reading through a social constructivist view. Effective reading in Dugan's model depends on creating a learning environment in which readers can learn from each other in what Dugan calls Transactional Literature Discussions (TLD). In TLD, teachers and students collaborate to build upon each other's responses and to deepen their understanding of the text.

Hardebeck (2006) defines reading comprehension strategies as tools or plans for facilitating and extending comprehension. Reading comprehension strategies can help readers remember the key points, distinguish the necessary and unnecessary information, think about the main idea and comment on the subject matter. Good readers use lots of strategies before, during and after reading (Dogan, 2002). 
The reading process gives rise to the issue of reading strategies. ESL/EFL learners usually employ a number of language learning strategies during their reading process. Those strategies involve cognitive, metacognitive, compensation, memory, affective, and social strategies (Chamot and O'Malley 1994; Crandall et al.2002; Oxford 1990).

As Cordero-Ponce (2000) explains, "summarization is perhaps one of the most significant and encompassing of all reading strategies available to the learner for effective studying and comprehension" (p.330)

According to McNamara (2004), describing the text in one's own words allows the reader to transform the material into a representation, and process the basic structure and of the sentence to transform the verbatim text into more familiar words (Schumaker, Denton and Deshler, 1984).

As a comprehension fostering activity, the process of summarization focuses attention on the central information of the text and provides the reader with a conceptual framework that facilitates memory and comprehension (Cordero-Ponce, 2000).

Summarization is based on Strategy intervention model (SIM) which deals with students' difficulties by teaching them to use strategies (Palincsar, 1987; Deshler, Schumaker, Lenz, and Ellis, 1984). The main focus of the SIM strategy is not increasing content knowledge, but rather, knowing how to learn through instruction in the summarization strategy

A theoretical explanation of how summarizing information promoted deep comprehension and learning was provided by Kintsch and van Dijk's (1978) model of discourse comprehension. Specifically, summarizing contributed to the goal of constructing a solid foundation of factual and conceptual knowledge because it served to reinforce the memory representation of the content beyond that achieved through reading (Van Dijk\&Kintsch, 1983).

There is little consensus among researchers regarding the extent to which the acquisition of knowledge of grammar among L2 learners is assisted by innate linguistic ability (Gass\&Schacter, 1989). However, the role of grammar in L2 reading has not received much attention by researchers (Alderson, 1984; Nassaji, 2007; Shiotsu\& Weir, 2007; Urquhart \& Weir, 1998). On the one hand, this may be attributable to the very nature of reading as a receptive language skill for comprehending the messages of the texts. Thus, knowledge of structure was regarded to have less to do with comprehending a text than levels of other components such as vocabulary, background knowledge, and reading strategies (Han \&D’Angelo, 2009; Urquhart \& Weir, 1998).

Barry and Lazarte (1995, Nation \&Snowling (2000) suggested that grammatical competence is crucial to constructing propositions across clauses without taxing the limited working memory capacity and to bringing relevant background knowledge into the reading task.

Alderson (1993) reviewed the data from the English Language Testing Services (ELTS) Revision Project and found a considerable overlap between scores on the grammar test and the reading test. In a similar vein, in Kuhn and Stahl's (2003) review of theories and research on reading instruction, training L2 readers to parse sentences into meaningful phrases and providing them with already syntactically segmented texts were revealed to promote L2 reading comprehension to a significant level.

On the other hand, Tunmer (1988) revealed no direct link between syntactic awareness and comprehension but simply an indirect one.

Urquhart and Weir (1998: 60-61) said that sentence analysis is necessary for sentence reading as proved by omitting most function words and all inflectional morphemes, including shifting words in sentences. However, this analysis must occur automatically to have reading fluency, and according to Grabe and Stoller (2002: 220) it takes thousands of hours of practice to do sentence parsing automatically.

The Syntactic Deficit Hypothesis (SDH) demonstrated the importance of syntactic skills in reading development (e.g., Bowey, 1986; Demont\&Gombert, 1996; Tunmer, 1988) according to this hypothesis, even though learning to speak and learning to read are continuous processes, the hypothesis asserts that reading requires the ability to process more structures than does early speech development.

Reading complex documents in order to answer questions is a common learning situation that modifies the reading processes as described by general comprehension models. Current studies demonstrate that when students experience explicit instruction of comprehension strategies, it improves their comprehension of new texts and topics.Question Answer Relationships (QAR) teaches students how to decipher what types of questions they are being asked and where to find the answers to them (Raphael, 2005).

According to Au \& Raphael (2005), the use of Question Answer Relationships (QAR) provides a framework for helping the students make the largely invisible process of listening and reading comprehension visible by giving students a language for talking about text. This type of approach falls under Cummins' (2006) Cognitive Academic Language Proficiency (CALP); this is the language needed to interpret and attain meaning. Cummins (2006) argues that proficiency requires growth in multiple areas simultaneously, this is often referred to the five C's: communication (listening and speaking), critical thinking (using graphic organizers, making inferences and using metacognition), context (participation structures), and culture (development and sustaining of supportive peer interactions) (Diaz-Rico \& Weed, 2006).

The finding of the QAR strategy is based on three ideas. The first one is the zone of proximal development which states that students of different age levels benefit from different amounts and types of QAR instruction (Raphael, 2005). The second idea is the gradual release of responsibility. The teacher starts from modeling, guiding students, to providing 
opportunities for the students to try the strategy on their own. The last idea is metacognition; Students need to be explicitly taught the answers to the questions to increase the likelihood of independent strategy use (Raphael, 2005).

Since there is no agreement among Iranian English teachers on the value of summarization tasks, syntactic structure training, and question-answer relationship, this research was conducted to compare the effects of three strategies on the reading comprehension ability of EFL learners in Iran.

\section{Research Questions}

The study addresses the following research questions:

1. Is there any significant difference between the effects of summarizing, question-answer relationship strategy, and syntactic structure identification training on the reading comprehension?

2. Does question-answer relationship result in better comprehension of reading texts?

3.Does summarization of English passages result in better comprehension of reading texts?

4. Does syntactic structure training result in better comprehension of reading texts?

\section{Method}

\subsection{Subjects}

To conduct the present research, three groups each consisting of 20 students of intermediate level based on the placement test were selected and treated as the experimental groups. The majority being from 18 to 25 years of age, 24 of them were men and 36 were women. All participants were foreign language learners of English. The students in intact English language classes were randomly divided into three groups, with each group receiving one of the three strategies for treatment

\subsection{Materials}

The following materials were used for the purpose of this study:

English placement test. This test comprised of listening, vocabulary, and grammar sections. The test was designed to the level of the students in the light of the pilot study results. It drew on past papers of the Cambridge First Certificate for students used in Cambridge University.

Pretest and posttest. The pretestconsisted of three English passages of comparable length (about 300 words) along with twenty multiple choice. The book was Reading Through Interaction seriesby Hartmann and Kirn. No changes or modifications were made to the texts.

A test administration similar to the pretest was used as posttest after two weeks at the end of the treatment. It was an English comprehension test consisting of three English tests selected form Reading Through Interaction seriesby Hartmann and Kirn with twenty multiple choice questions.

Reading comprehension tests. During five sessions of treatment, five English reading passages of appropriate length (about 300 words) from Developing Reading Skills by Linda Markstein and Louise Hirasawa were given to the subjects in the first group to summarize as their homework and the second group to answer the questions by using QAR strategy. The subjects in the third experimental group were given five passages to identify the syntactic structure and answer the comprehension questions.

\subsection{Procedures}

Three reading comprehension passages with 20 multiple choice question were administered to students as a pretest. The scores the two classes obtained on the test were statistically analyzed and compared to figure out whether there was any difference between the experimental groups.

\subsubsection{Experimental Group One}

The treatment phase consisted of five sessions of instruction. The students in the first experimental group were supposed to summaries the texts. First, they were provided with explicit instruction of the summarization skills with someexamples. The subjects delivered their summaries in written form. Each session, one passage was considered to be summarized. In order to provide the subjects with feedback on how they performed on the summary assignments, all the summaries were scored for the number of main ideas included, the efficiency of summarization, the application of summarization rules and the manner of organization and summary writing. The feedback given by the teacher consisted of some examples of the strong points of the summary as well as guidelines for improving the subject's summary production.

\subsubsection{Experimental Group Two}

In order to grasp the concept of QAR, the intervention began with direct explicit instruction, progressed into modeling, then guided instruction and finally independent application.

In the beginning sessions, the students were familiarized with the language of QAR and how it is applied to reading comprehension through a series of examples. Furthermore the students learned different steps they should go through to find the answer. After the explicit instruction, the subjects were asked to work in pair, find the types of the questions related to the passage and explain the reason it fit that category. For the second session, the students were supposed to read the passage and write questions with three possible answers to make a multiple-choice question. When they 
became more comfortable with the language and components of QAR, they identified question types and determined what steps they would take to answer them. They also explained the reason they chose the type of QAR. At the end of each session, they were provided with feedback on how they performed.

\subsubsection{Experimental Group Three}

The experimental group three was trained to identify syntactic structure of sentences (telling types of phrases and clauses, and sentences), core parts of sentences, head words and modifiers, as well as answering comprehension questions.

The teacher introduced the syntactic structures by giving some examples. Each session one or two syntactic structures were taught depending on the complexities of the structures. Then the syntactic structures of the sentences in a passage were identified by the teacher as a model, and also the questions were answered. Each session the syntactic structures which have been taught before were reviewed by the instructor. To provide feedback, the papers were scored by the researcher and were given back to them.

\subsubsection{Data Analysis}

Following the administration of the reading comprehension posttest which consisted of three English reading passages along with 20 multiple choice items, the student's performance on the posttest was scored.

To gain insight into the characteristics of the sample groups, the scores obtained by each group were put in various formulas of descriptive statistics. The t-test formula was used for the meaningful comparison of the pretest and posttest results. Furthermore, the ANOVA test was used to determine whether there was significant difference between the groups. Then pair wise comparison of groups was done to determine which group had the best result.

\section{Results}

\subsection{The ComparisonofThree Groups}

The first research question is "Is there any significant difference between the effects of summarizing, question-answer relationship strategy, and syntactic structure identification training on reading comprehension?"

Table 1. Analysis of Variance on the Posttest

\begin{tabular}{lccccc}
\hline Source of variance & SS & d.f. & MS & F & Sig. \\
\hline Within group & 171.633 & 2 & 85.817 & 18.188 & .000 \\
\hline Between group & 268.950 & 57 & 4.718 & & \\
\hline Total & 440.583 & 59 & & & \\
\hline
\end{tabular}

As table 1 indicates, the calculated value of Sig for the performance of the three groups on the posttest was .000 which was lower than .05; therefore it was concluded that there is significant difference between the three strategies. In other words, the null hypothesis that "there is no significant difference between the three groups." is rejected. Furthermore, the pair wise comparison of the three groups was done in order to figure out whether there is significant difference between them. Table 2 presents the result.

\subsection{The Pair wise Comparison of the Groups}

Table 2. Multiple comparison of Groups on the Posttest

\begin{tabular}{lccc}
\hline Group(I) & Group(J) & Mean Differences (I-J) & Sig. \\
\hline 1 & 2 & -3.750 & .000 \\
& 3 & -.350 .867 & \\
\hline 2 & 1 & 3.750 & .000 \\
& 3 & 3.400 & .000 \\
\hline 3 & 1 & .350 & .867 \\
& 2 & -3.400 & .000 \\
\hline
\end{tabular}

As table 2 shows, the groups were compared two by two by the use of mean differences. The calculated value of Sig for the performance of group one and two which are .867 and .000 shows that the two groups were different. Therefore it was concluded that there is significant difference between groups which used summarizing and question-answer relationship. The calculated value of Sig for the performance of the group two and three are .000 and .867 which indicates that there is significant difference between question-answer relationship and syntactic structure training. On the contrary, the comparison of group one and three shows that the calculated value of Sig is .000 and lower than .05; 
therefore it was concluded that there is no significant difference between summarizing and syntactic structure training. Figure 4.2 below shows the mean scores of students on the posttest.

\subsection{The comparison of pretest and posttest}

To determine the effect of treatment on the students' scores on the posttest, the following questions were suggested.

1. Does the use of question-answer relationship result in better comprehension of reading texts?

2. Does the summarization of English passages result in better comprehension of reading texts?

3. Does the use of syntactic structure training result in better comprehension of reading texts?

Table 3. The Comparison of the Mean Differences of the ThreeGroup Scores on the Pretest and Posttest

\begin{tabular}{lcccc}
\hline & Mean Differences & $\mathrm{t}$ & $\mathrm{d} . f$. & Sig. \\
\hline Group One & 1.5 & 9.747 & 19 & .000 \\
\hline Group Two & -2.650 & -20.184 & 19 & .000 \\
\hline Group Three & 1.2 & 8.718 & 19 & .000 \\
\hline
\end{tabular}

The use of " $t$ " test for the mean scores of each group on the pretest and posttest showed that since the calculated Sig value is lower than .05 , it was concluded that, the null hypotheses that "the use of the three strategies do not result in better comprehension of reading texts." are rejected.

\section{Conclusion, Discussion, and Suggestion}

The purpose of this study was to compare the effects of summarizing, question-answer relationship, and syntactic structure training on the reading comprehension. To recapitulate the findings and the conclusion of this study, it can be claimed that there was a statistically meaningful difference between the mean achievements of the three groups in favor of the group two which the participants received the QAR strategy. The findings also demonstrated that the treatment was effective in three groups. Regarding the effect of syntactic structure training, the result was in consistence with previous studies' findings (Cowan, 1976; Berman, 1984; Shiotsu \& Weir, 2007). On the contrary, some of the studies showed that reading comprehension is little dependent on a syntactic analysis of the texts (Ulijn \& Kempen, 1976). Furthermore, the result of the study confirmed the Syntactic Deficit Hypothesis according to which reading demands more syntactic knowledge than beginning readers possess.

The results also demonstrated that summarization instruction had a positive effect on the reading comprehension. Although the result was not compatible with the previous studies (Brown \& Day, 1983; Garner, 1985), the other studies have shown the importance of summarizing as a tool for improving reading comprehension. Moreover, the strategy was in line with the SIM strategy which claimed that students learn to acquire, retrieve, manipulate, store, remember, and express academic content information in an organized and a systematic manner.

The pair wise comparison of the groups also illustrated that the use of question-answer relationship had significant effect on the reading comprehension comparing with the other groups. The finding is consistent with previous studies (Graesser, Singer, \&Trabasso, 1994; Kintsch, \& Saunders, 1978) which suggested that question-answer relationship seems to activate prior knowledge and allows students the opportunity to tap into prior knowledge and use it to their advantage. Furthermore, results showed that the QAR strategy falls under Cummins' (2006) Cognitive Academic Language Proficiency (CALP), and it is also based on three ideas: The zone of proximal development, the gradual release of responsibility, and metacognition (Raphael, 2005).

Finally the pair wise comparison of the groups showed that syntactic structure training and summarization assignment had no significant influence on the reading comprehension performance of the other groups. The result was in vein with Robertson \& Nunn (2009), and Ajaja (2011) study which showed that the two strategies had no significant effect on the reading comprehension ability comparing with other strategies. The research has shown that there are more strategies that affect reading comprehension. Hence, it seems reasonable to conduct more research to compare the other strategies with QAR strategy in order to find out whether it is effective in comparison with the others. Furthermore, Since the research has been limited to the students of intermediate level, further research is recommended to figure out the effect of QAR strategy on the learners of various levels especially lower levels.

\section{Reference}

Alderson, J. C. (1993). The relationship between grammar and reading in English for academic purposes test battery. In D. Douglas \& C. Chapelle (Eds.), A new decade of language testing research: Selected papers fromthe 1990 Language Testing Research Colloquium (pp. 203-219). Alexandria, VA: TESOL.

Au, K.H., \&Highfield, K., \& Raphael, T.E. (2006).QAR now: a powerful and practical framework that develops comprehension and higher-level thinking in all students. New York, NY: Scholastic, Inc.

$\mathrm{Au}, \mathrm{K}$. H. \& Raphael, T. E. (2005).QAR: enhancing comprehension and test taking across grades and content areas. The Reading Teacher, 59(3), 206-221. 
Barry, S., \& Lazarte, A. A. (1995). Embedded clause effects on recall: Does high priorknowledge of content domain overcome syntactic complexity in students of Spanish?TheModern Language Journal, 79, 491-504.

Bernhardt, E. (1986). Cognitive processes in L2: An examination of reading behaviors. In J.Lantolf \& L. Labarca (Eds.), Research in second language learning: Focus on the classroom (pp. 35-51). Norwood, NJ:

Ablex.

Bowey, J. A. (1986). Syntactic awareness in relation to reading skill and ongoing reading comprehension monitoring. Journal of Experimental Child Psychology, 41(2), 282-299.

Demont, E., \&Gombert, J. E. (1996). Phonological awareness as a predictor of reading skills and syntactic awareness as predictor of comprehension skills. British Journal of Educational Psychology, 66, 315-332.

Chamot, A.U., and J.M. O’Malley (1994).Language Learner and Learning Strategies. In N. Ellis (Eds.), Implicit andExplicit Learning of Languages (pp. 371- 92). London: Academic Press

Corder-Ponce, W.L. (2000). Summarization interaction: effects on foreign language comprehension and summarization of expository texts. Reading research and instruction, 39 (4), 329 - 350.

Crandall, Jaramillo, Olsen, and Peyton (2002).Using Cognitive Strategies to DevelopEnglish Language and Literacy.Retrieved from http://www.ericdigests.org/2003-3/using.htm.

Cummins, J. (1979). Linguistic interdependence and the educational development of bilingual children. Review of Educational Research, 49 (2), 222-251.

Deshler, D. D., Schumaker, J. B., Lenz, B. K., and Ellis, E. (1984). Academic and cognitive interventions for LD adolescents: Part II. Journal of Learning Disabilities, 17, 170-179.

Diaz-Rico, L.T., \& Weed, K.Z. (2006). The crosscultural language and academic development handbook: Boston, MA: Pearson Education, Inc.

Dogan, B. (2002). The effects of strategy teaching on reading comprehension, motivation and retention in coopertaive and traditional classes. Unpublished Doctorate Thesis, DokuzEylul University, Institute of Educational Sciences, Izmir.

Dugan, J. (1997). Transactional literature discussions: Engaging students in the appreciation and understanding of literature. The Reading Teacher, 51, 86-96.

Grabe (1991).Current developments in second language reading research. TESOL Quarterly.

Grabe, W. and Stroller, L.F. (2002).Teaching and Researching Reading.Harlow, Essex: Pearson Education Ltd.

Graesser, A. C., Singer, M., \&Trabasso, T. (1994). Constructing inferences during narrative text comprehension. Psychological Review, 101(3), 371e395

Hardebecek, M. M. (2006). Effectiveness and usage of reading comprehension strategies for second grade title 1 students. Unpublished Master Thesis, Minesota State University, Education Department, Minnesota.

Kintsch, W., \& van Dijk, T.A. (1978). Toward a model of text comprehension and production.Psychological Review, 85(5), 363-394.

Koda, K. (1988). Cognitive process in second language reading: Transfer of L1 reading skills and strategies. Second Language Research, 4, 133-156.

Kuhn, M. R., \& Stahl, S. A. (2003). Fluency: A review of developmental and remedial practices. Journal of Educational Psychology, 95, 3-21.

McNamara, D. S. (2004). SERT: Self-Explanation Reading Training. Discourse Processes, 38, 1-30.

Nation, K. \&Snowling, M. (2000). Factors influencing syntactic awareness skills in normal readers and poor comprehenders. Applied Psycholinguistics, 21, 229-241.

Oxford, R. (1990). Language Learning Strategies: What Every Teacher Should Know. New York: Newbury House.

Palinscar, A. S. (1987). Metacognitive strategy instruction. Exceptional Children, 53,118-124. Raphael, T.E. (1982). Question-answer strategies for children. The reading teacher.36, 186-190.

Resnick, L.B. (1984). Comparing and learning: Implications for a cognitive theory of instruction. In H.Mand1, N.L. Stein, \&T.Trabasso (Eds.), Learning and Comprehension of Text.(pp. 431- 443).Hillsdale. NJ: Erlbaum.

Schumaker, J. B., Denton, P.H., and Deshler, D.D. (1984).The paraphrasing strategy. Lawrence: University of Kansas.

Shahriari, S. (2002).Comparing the effect of oral and written summarization on the reading comprehension ability of Iranian high school students.

Tunmer, W. E., Herriman, M. L., \& Nesdale, A. R. (1988).Metalinguistic abilities and beginning reading. Reading Research Quarterly, 23(2), 134-158.

Urquhart, S. and Weir, C. (1998). Reading in a Second Language: Process, Product and Practice. New York: Longman. 